\title{
Advanced Remote Sensing Research
}

\section{Introduction}

"Remote sensing" is a generic term for monitoring techniques that collect information without being in physical contact with the object of study. Overhead imagery from aircraft and satellite sensors provides the most common form of remotely sensed data and records the interaction of electromagnetic energy (usually visible light) with matter, such as the Earth's surface (fig. 1).

Remotely sensed data are fundamental to geographic science. The Eastern Geographic Science Center (EGSC) of the U.S. Geological Survey (USGS) is currently conducting and promoting the research and development of three different aspects of remote sensing science: spectral analysis, automated orthorectification of historical imagery, and long wave infrared (LWIR) polarimetric imagery (PI).

\section{Spectral Analysis of Vegetation and Water}

Because different materials absorb or reflect energy from different wavelengths of light in unique ways, the development of high spectral resolution sensors and analytical methods provides the ability to identify the presence or absence of target

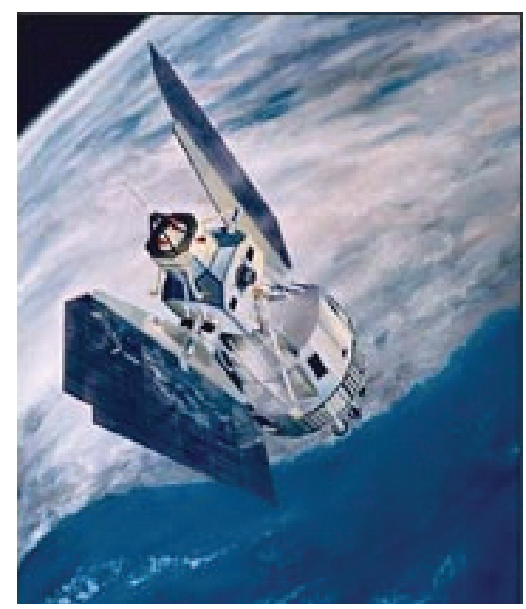

Figure 1. Artist's conception of Landsat 2 satellite in orbit; from National Aeronautics and Space Administration (NASA, 2008). Landsat 2 was operated by NASA from 1975 to 1982 and was followed by Landsats 3-7. The Landsat Data Continuity Mission (LDCM) being planned in 2008 is the latest program in three decades of Landsat data collection and will continue a long tradition of Earth observation and spectral analysis of the Earth's surface. NASA and the U.S. Geological Survey will cooperate on the LDCM. materials or conditions and to investigate physical and chemical processes at the Earth's surface. Vegetation health and water quality are two important science issues that will be investigated by using hyperspectral remote sensing techniques (fig. 2).
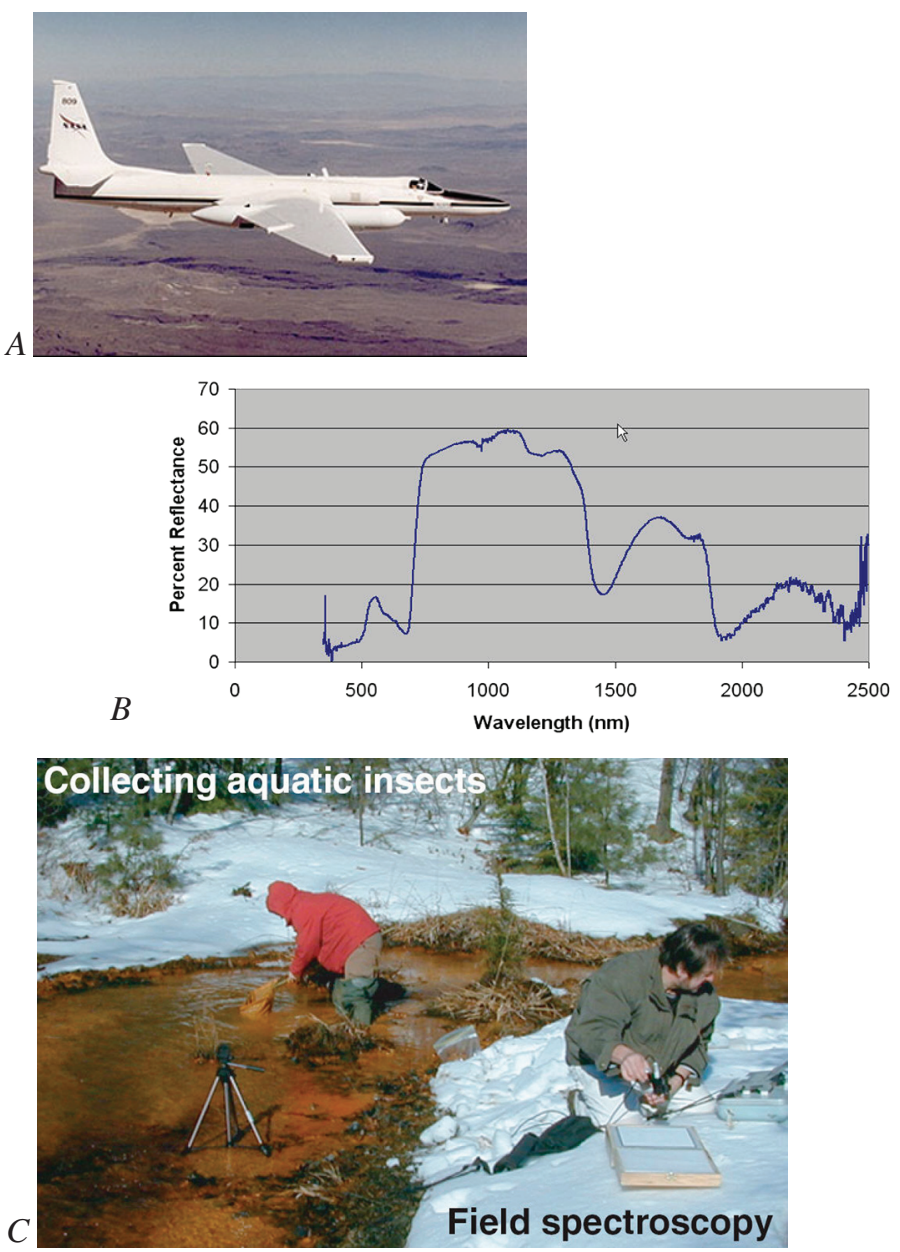

Figure 2. Multispectral and hyperspectral data collections from a variety of field and overhead instruments are being utilized to analyze water and vegetation characteristics. A, NASA ER-2 research aircraft that carries the AVIRIS (Airborne Visible/Infrared Imaging System) hyperspectral imaging sensor above the bulk of the stratosphere at altitudes from 60,000 to 70,000 feet. $B$, Graph of hyperspectral data (percent reflectance vs. wavelength) showing the spectra of Chinese spider fern (Pteris multifida). C, Field spectrometer measuring reflections from water affected by acid mine drainage. Spectra from laboratory, field, and overhead instruments record the same energy interactions at different scales. Image A from Short (2007); image B from Terrence Slonecker, USGS; image $C$ by Norrie Robbins, USGS. nm, nanometer. 
"Hyperspectral" refers to a variety of remote sensing techniques that collect reflected or emitted electromagnetic energy in hundreds of narrow, contiguous bands that record the interaction of photons with the molecular structure of the material being sensed. When processed, the resulting plot of these energy interactions, called "spectra," can be used to identify unique elements, minerals, water-quality parameters, and vegetation health and stress.

Remote sensing analyses of vegetation and water provide indicators of overall ecosystem condition, environmental stress, and landscape change at local, regional, and global scales. Advances in remote sensing imaging systems and data processing technologies have led to an increase in the use of this information to answer scientific questions related to vegetation and water issues, including the following:

- Detection of plant or water contaminants

- Identification of plant species

- Detection of plant stress

- Determination of chemical concentrations in tree canopies or leaves

- $\quad$ Research on hyperspectral and polarimetric applications

- Monitoring agricultural processes

- Correlation of plant chemistry with geology (geobotany and biogeochemistry)

- Use of infrared data

- Monitoring changes in coastal and wetland areas

- Monitoring droughts and wildfires

Combinations of techniques such as laboratory chemistry, field sampling, field spectroscopy, and overhead hyperspectral imaging are being used to detect the signatures of specific contaminants and stress conditions at local to regional scales (fig. 2). Studies include the spectral analysis of heavy-metal contamination in soils and vegetation and the analysis of nitrogen loading in small watersheds.

\section{Automated Orthorectification of Historical Imagery}

Overhead imagery in various forms has been routinely collected since the 1930s, and some images are available from even earlier. Each image represents a frozen moment in time and can be used to develop a temporal analysis of changes in surface conditions for a period of 70 years or more (fig. 3). One of the primary scientific tools for the analysis of temporal landscape change can be found in the vast archives of airborne and satellite images held by the USGS Center for Earth Resources Observation and Science (EROS), the USGS Advanced Systems Center (ASC), and other public and private collections (Slonecker and others, 1999).

Understanding landscape change over time is fundamental to many aspects of geographic research (U.S. Geological Survey, 2002). However, realizing the fundamental value of historical imagery for landscape-change studies is still severely restricted because most of this imagery exists only in analog formats and lacks geospatial registration and cartographic fidelity. A significant level of effort is required to convert analog images into digital geospatial formats that are compatible with a geographic information system (GIS).

Orthorectification is the photogrammetric process of removing inherent distortions in aircraft or satellite imagery to create new digital images that are geometrically accurate and referenced to an Earth coordinate system. Until recently, the process required the decisions and actions of a skilled photogrammetric technician and was time consuming and resource intensive.

Recent advances in pattern recognition, database management, and digital photogrammetric processing have enabled the development of a completely automated orthorectification capability. This automated capability has the potential to transform massive holdings of analog and unregistered imagery

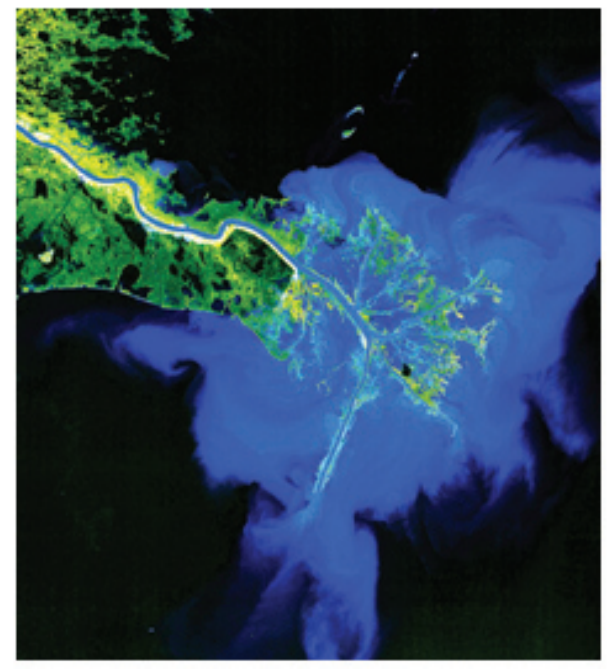

1973

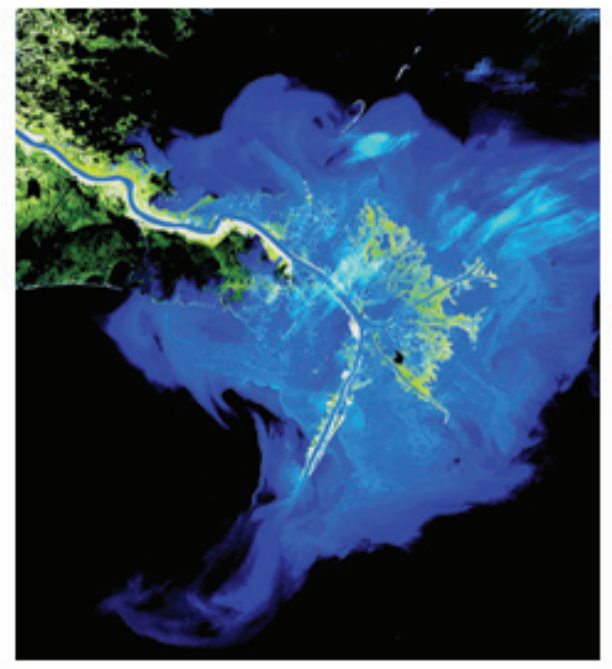

1989

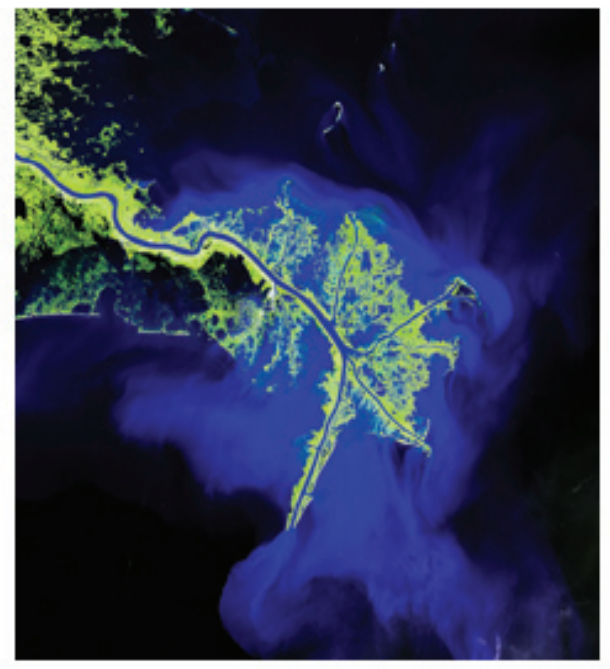

2003

Figure 3. Temporal sequence of Landsat images showing 30 years of sediment deposition on the Mississippi River Delta. From U.S. Geological Survey (2006). 
into digital, geospatial, GIS-compatible image data that can be managed, referenced, and retrieved in a geospatial database. Such databases will provide critical temporal landscape-change information for climate-change research and other long-term studies.

\section{Long Wave Infrared (LWIR) Polarimetric Imagery (PI)}

Long wave infrared polarization is an experimental remote sensing technique that seeks to characterize the structural, as opposed to reflective, characteristics of a target surface. It has the potential to identify objects or situations that are not recognizable by the human eye (fig. 4) and can improve mapping of forest understory land uses, a constant problem in remote sensing (Felton and others, 2007).
Imaging polarimetry measures the vector (directional) nature of reflected or emitted energy in an image. In contrast to images from conventional sensors that record spectral information about the materials in a scene, polarimetric images have data on surface features, patterns, shapes, and roughness (Tyo and others, 2006).

Passive imaging polarimetry has recently emerged as a potentially powerful new enhancement to the toolbox of remote sensing capabilities. Passive imaging polarimetry may help researchers to provide better understory estimates of impervious surfaces and other manmade objects.

\section{By Terrence Slonecker, John W. Jones, Susan D. Price, and Dianna Hogan}
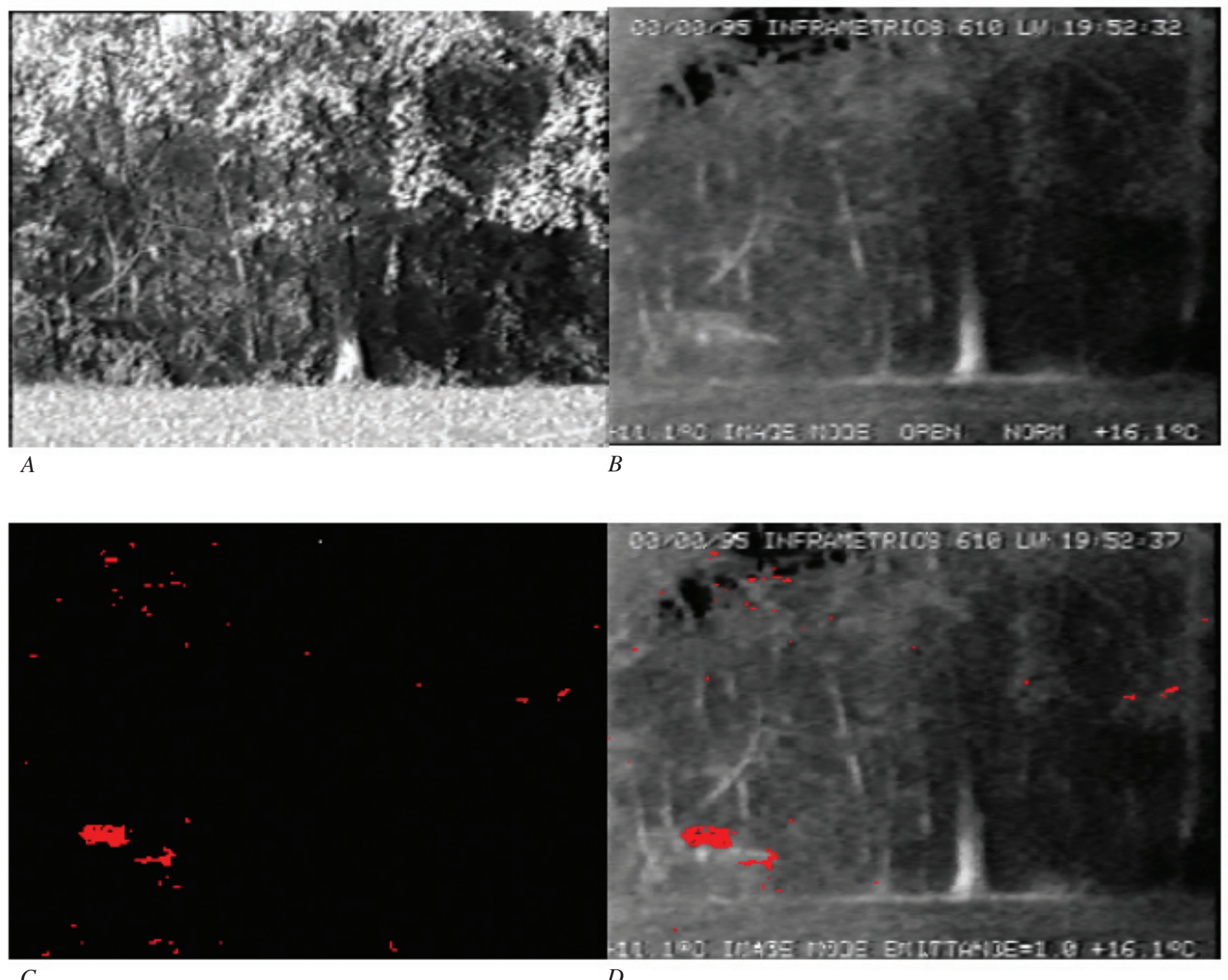

Figure 4. Four images of the same site showing the value of long wave infrared (LWIR) polarimetric images for identifying manmade objects amid trees. $A$, Visible image. $B$, LWIR thermal image. $C$, Processed polarimetric image, which shows a measure of the difference between horizontally and vertically polarized radiation. $D$, Fusion of the LWIR image and the processed polarimetric image, revealing the presence of a hidden vehicle. From Felton and others (2007, fig. 1). 


\section{References Cited}

Felton, Melvin, Gurton, K.P., Ligon, David, and Raglin, Adrienne, 2007, Discrimination of objects within polarimetric imagery using principal component and cluster analysis: U.S. Army Research Laboratory [Report] ARL-TR-4216, 22 p., available online at http://www.arl.army.mil/arlreports/2007/ ARL-TR-4216.pdf.

National Aeronautics and Space Administration (NASA), 2008, Landsat 2: National Aeronautics and Space Administration Web page at http://landsat.gsfc.nasa.gov/about/landsat2.html.

Short, N.M., Sr., 2007, Collecting data at the surface-Ground truth; The "multi" concept; Hyperspectral imaging spectroscopy, section 13 of Short, N.M., Sr., Remote sensing tutorial: National Aeronautics and Space Administration publication available only online at http://rst.gsfc.nasa.gov/Sect13/ Sect13_4.html. (Accessed May 12, 2008.)

Slonecker, E.T., Lacerte, M.J., and Garofalo, David, 1999, The value of historical imagery: Earth Observation Magazine, v. 8, no. 6, p. 39-41.

Tyo, J.S., Goldstein, D.L., Chenault, D.B., and Shaw, J.A., 2006, Review of passive imaging polarimetry for remote sensing applications: Applied Optics, v. 45, no. 22, p. 5453-5469.

U.S. Geological Survey, 2002, National Civil Applications Program: U.S. Geological Survey Fact Sheet 121-02, 2 p.

U.S. Geological Survey, 2006, Tracking change over time; A classroom activity: Sioux Falls, S. Dak., U.S. Geological Survey, 1 CD-ROM. (Also available online at http://eros.usgs. gov/kids/documentation/.)

\section{For further information, please contact:}

Terrence Slonecker

Eastern Geographic Science Center

U.S. Geological Survey

521 National Center

12201 Sunrise Valley Drive

Reston, VA 20192

Telephone: 703-648-4289

E-mail: tslonecker@usgs.gov

John W. Jones

Telephone: 703-648-5543

E-mail: jwjones@usgs.gov

Susan D. Price

Telephone: 703-648-6692

E-mail: sprice@usgs.gov

Dianna Hogan

Telephone: 703-648-7240

E-mail: dhogan@usgs.gov

Please visit the Eastern Geographic Science Center Web page: http://erg.usgs.gov

Any use of trade, product, or firm names in this publication is for descriptive purposes only and does not imply endorsement by the U.S. Government. 